\title{
Halo-Substituted Chalcones and Azachalcones Inhibited Lipopolysaccharited-Stimulated Pro-Inflammatory Responses through the TLR4-Mediated Pathway
}

\author{
Tzenge-Lien Shih ${ }^{1}$, Ming-Hwa Liu ${ }^{2}$, Chia-Wai Li ${ }^{1}$ and Chia-Feng Kuo ${ }^{2, *}$ (D) \\ 1 Department of Chemistry, Tamkang University, Tamsui Dist., New Taipei City 251, Taiwan; \\ tlshih@mail.tku.edu.tw (T.-L.S.); 602180076@s02.tku.edu.tw (C.-W.L.) \\ 2 Department of Food Science, Nutrition, and Nutraceutical Biotechnology, Shih Chien University, \\ Zhongshan Dist., Taipei 104, Taiwan; a0141011@g2.usc.edu.tw \\ * Correspondence: drkuo@g2.usc.edu.tw; Tel.: +886-2-2538-1111 (ext. 6214); Fax: +886-2-2533-4789
}

Received: 4 February 2018; Accepted: 4 March 2018; Published: 7 March 2018

\begin{abstract}
A series of B-ring, halo-substituted chalcones and azachalcones were synthesized to evaluate and compare their anti-inflammatory activity. Mouse BALB/c macrophage RAW 264.7 were pre-treated with $10 \mu \mathrm{g} / \mathrm{mL}$ of each compound for one hour before induction of inflammation by lipopolysaccharide $(1 \mu \mathrm{g} / \mathrm{mL})$ for $6 \mathrm{~h}$. Some halo-chalcones and -azachalcones suppressed expression of pro-inflammatory factors toll-like receptor 4 (TLR4), I $\mathrm{kB}-\alpha$, transcription factor p65, interleukine $1 \beta$ (IL-1 $\beta)$, IL-6, tumor necrosis factor $\alpha$ (TNF- $\alpha$ ), and cyclooxygenase 2 (COX-2). The present results showed that the synthetic halo-azachalcones exhibited more significant inhibition than halo-chalcones. Therefore, the nitrogen atom in this series of azachalcones must play a more crucial role than the corresponding C-2 hydroxyl group of chalcones in biological activity. Our findings will lay the background for the future development of anti-inflammatory nutraceuticals.
\end{abstract}

Keywords: azachalcones; chalcones; anti-inflammation; toll-like receptor 4

\section{Introduction}

Inflammation is an immune response to injury and infection. Inflammation is considered to be beneficial when it is short term and under control; however, chronic production of radicals by inflammation causes oxidative damages and leads to chronic diseases [1-5]. Natural products that possess anti-inflammatory properties are valuable phytomedicine.

Chalcones belong to the flavonoid family. They are widely distributed in natural products and exhibit a variety of biological activities, including anti-oxidation, anti-inflammation, chemoprevention, cardioprotection, antidiabetics, and neuroprotection [6-14]. Novel chalcones with biological activities have been designed and synthesized [15-21].

The skeleton of chalcones possesses a 1,3-diphenyl-2E-propene-1-one framework (Figure 1). The hydroxy and methoxy groups are the most common substituted groups on either or both rings in chalcones that show good antitubulin and cytotoxic activity [22]. Among them, the nearby $\mathrm{C}^{\prime}$ hydroxyl moiety in ring A contributed hydrogen bonding to the carbonyl group, leading to the stabilization of the planar structure [23]. The most common strategy for the synthesis of chalcones is Claisen-Schmidt condensation [24,25]. 
<smiles>O=C(O)c1ccccc1C=Cc1ccccc1</smiles>

Chaclone<smiles>O=C(/C=C/c1ccccc1)c1ccccn1</smiles>

Azachaclone

Figure 1. Structures of chalcones and azachalcones.

Azachalcone is another class of the chalcone family in which the carbons of either rings A or $\mathrm{B}$ or both were replaced with a nitrogen atom. Because of their structural similarity, azachalcones were synthesized with the same strategy as for chalcones, in which the substituted acetophenone was replaced with 2-acetyl pyridine [26,27]. Studies have shown that azachalcones possess anti-bacterial, anti-inflammatory, and anti-cancer properties [28-31]. Azachalcones also served as precursors for synthesis of pyrazolines and pyrazoles [32].

The halo-substituted chalcones and azachalcones are not naturally occurring compounds [33]. The halogen substitution in ring B of chalcones alters the electron distribution owing to its high electronegativity and dipole moment, which can influence the biological activity. The aim of this study is to synthesize novel, monohalogen-substituted chalcones and azachalcones in various positions in ring $B$ and evaluate their anti-inflammatory activity. To the best of our knowledge, this article is the first report in a systematic study of the biological activities of monohalogen-substituted chalcones $(7 \mathbf{a}-\mathbf{i})$ and azachalcones $(\mathbf{9 a}-\mathbf{i})$ together (vide infra). The anti-inflammatory activities of synthetic chalcones and azachalcones were also compared with those of synthetic, naturally occurring chalcones 1-4 (Figure 2), which were synthesized; their spectroscopic data were all in agreement with the reported values.<smiles>O=C(/C=C/c1ccccc1O)c1ccccc1</smiles>

1<smiles>O=C(/C=C/c1ccc(O)cc1)c1ccccc1</smiles>

2<smiles>O=C(/C=C/c1ccccc1)c1ccccc1O</smiles>

3<smiles>COc1ccc(/C=C/C(=O)c2ccccc2)cc1</smiles>

4

Figure 2. Natural chalcones 1-4.

\section{Results and Discussion}

\subsection{Synthesis of Halo-Substituted Chalcones $\mathbf{7 a}-\mathbf{i}$ and Azachalcones $\mathbf{9 a - i}$}

In order to optimize the reaction condition, we repeated the synthesis of a series of halo-substituted chalcones $\mathbf{7 g}-\mathbf{i}$ from $\mathbf{5}$ and halobenzaldehyde $\mathbf{6 a}-\mathbf{i}$ by Claisen-Schmidt condensation (Figure 3). The optimized yields were listed in Table 1.<smiles>CC(=O)c1ccccc1O</smiles>

5<smiles>[X]c1ccc(C=O)c([X])c1[X]</smiles>

6a-i<smiles>[X]c1ccc(/C=C/C(=O)c2ccccc2O)c([X])c1[X]</smiles>

7a-i
a. $X=H, Y=H, Z=F$
d. $\mathrm{X}=\mathrm{H}, \mathrm{Y}=\mathrm{F}, \mathrm{Z}=\mathrm{H}$
b. $\mathrm{X}=\mathrm{H}, \mathrm{Y}=\mathrm{H}, \mathrm{Z}=\mathrm{Cl}$
e. $X=\mathrm{H}, \mathrm{Y}=\mathrm{Cl}, \mathrm{Z}=\mathrm{H}$
c. $\mathrm{X}=\mathrm{H}, \mathrm{Y}=\mathrm{H}, \mathrm{Z}=\mathrm{Br}$
f. $\mathrm{X}=\mathrm{H}, \mathrm{Y}=\mathrm{Br}, \mathrm{Z}=\mathrm{H}$
g. $X=F, Y=H, Z=H$
h. $\mathrm{X}=\mathrm{Cl}, \mathrm{Y}=\mathrm{H}, \mathrm{Z}=\mathrm{H}$
i. $\mathrm{X}=\mathrm{Br}, \mathrm{Y}=\mathrm{H}, \mathrm{Z}=\mathrm{H}$

Figure 3. Claisen-Schmidt condensation in synthesis of chalcones $7 \mathbf{a}-\mathbf{i}$.

Azachalcones $\mathbf{9 a - i}$ were synthesized from $\mathbf{8}$ and corresponding $\mathbf{6 a}-\mathbf{h}$ (Figure 4 ) as reported recently [33]. The structures of synthetic chalcones $7 \mathbf{a}-\mathbf{i}$ and azachalcones $9 \mathbf{a}-\mathbf{i}$ are listed in Figure 5 . The ${ }^{1} \mathrm{H}$ and ${ }^{13} \mathrm{C}$ NMR data for compounds $7 \mathbf{a}-\mathbf{i}$ and $\mathbf{9 a}-\mathbf{i}$ are available as supporting materials. 
Table 1. Optimization in synthesis of chalcones $\mathbf{7 a - i}$.

\begin{tabular}{cccc}
\hline Entry & Compound & Time (h) & Yield $\%$ \\
\hline 1 & $\mathbf{7 a}$ & 14 & 92 \\
2 & $\mathbf{7 b}$ & 9 & 75 \\
3 & $\mathbf{7 c}$ & 15 & 82 \\
4 & $\mathbf{7 d}$ & 8 & 76 \\
5 & $\mathbf{7 e}$ & 13 & 67 \\
6 & $\mathbf{7 f}$ & 14 & 73 \\
7 & $\mathbf{7 g}$ & 13 & 85 \\
8 & $\mathbf{7 h}$ & 14 & 78 \\
9 & $\mathbf{7 i}$ & 15 & 73 \\
\hline
\end{tabular}

Condition: 5 (1 equiv.), $6 \mathbf{a}-\mathbf{i}$ (1.5 equiv.), $\mathrm{KOH}$ (3 equiv.), $\mathrm{EtOH}(0.2 \mathrm{M})$, and 0 to r.t.<smiles>[CH2+]C(=O)c1ccccn1</smiles>

8<smiles>[X]c1ccc(C=O)c([X])c1[X]</smiles>

6a-h<smiles>[X]c1ccc(/C=C/C(=O)c2ccccn2)c([X])c1[X]</smiles>

9a-i
a. $X=\mathrm{H}, Y=\mathrm{H}, \mathrm{Z}=\mathrm{F}(51 \%)$
b. $\mathrm{X}=\mathrm{H}, \mathrm{Y}=\mathrm{H}, \mathrm{Z}=\mathrm{Cl}(35 \%)$
d. $\mathrm{X}=\mathrm{H}, \mathrm{Y}=\mathrm{F}, \mathrm{Z}=\mathrm{H}(28 \%)$
e. $X=\mathrm{H}, Y=\mathrm{Cl}, Z=\mathrm{H}(46 \%)$
g. $X=F, Y=H, Z=H(35 \%)$
c. $\mathrm{X}=\mathrm{H}, \mathrm{Y}=\mathrm{H}, \mathrm{Z}=\mathrm{Br}(32 \%)$
f. $X=H, Y=B r, Z=H(46 \%)$
h. $X=C l, Y=H, Z=H(56 \%)$
i. $X=B r, Y=H, Z=H(41 \%)$

Figure 4. Conditions of synthesis of azachalcones $\mathbf{9 a - i .}$<smiles>O=C(/C=C/c1ccc(F)cc1)c1ccccc1O</smiles>

$7 a$<smiles>O=C(/C=C/c1cccc(F)c1)c1ccccc1O</smiles>

$7 d$<smiles>O=C(/C=C/c1ccccc1F)c1ccccc1O</smiles>

$7 g$<smiles>O=C(/C=C/c1ccc(F)cc1)c1ccccn1</smiles>

9a<smiles>O=C(/C=C/c1cccc(F)c1)c1ccccn1</smiles>

9d<smiles>O=C(/C=C/c1ccccc1F)c1ccccn1</smiles>

9g<smiles>O=C(/C=C/c1ccc(Cl)cc1)c1ccccc1O</smiles>

$7 b$<smiles>O=C(/C=C/c1cccc(Cl)c1)c1ccccc1O</smiles>

$7 e$<smiles>O=C(/C=C/c1ccccc1Cl)c1ccccc1O</smiles>

$7 \mathrm{~h}$<smiles>O=C(/C=C/c1ccc(Cl)cc1)c1ccccn1</smiles>

$9 b$<smiles>O=C(/C=C/c1cccc(Cl)c1)c1ccccn1</smiles>

$9 e$<smiles>O=C(/C=C/c1ccccc1Cl)c1ccccn1</smiles>

9h<smiles>O=C(/C=C/c1ccc(Br)cc1)c1ccccc1O</smiles>

$7 c$<smiles>O=C(/C=C/c1cccc(Br)c1)c1ccccc1O</smiles>

$7 f$<smiles>O=C(/C=C/c1ccccc1Br)c1ccccc1O</smiles>

$7 \mathbf{i}$<smiles>O=C(/C=C/c1ccc(Br)cc1)c1ccccn1</smiles>

$9 c$<smiles>O=C(/C=C/c1cccc(Br)c1)c1ccccn1</smiles>

9f<smiles>O=C(/C=C/c1ccccc1Br)c1ccccn1</smiles>

$9 i$

Figure 5. Chemical structures of synthetic chalcones $7 \mathbf{a}-\mathbf{i}$ and azachalcones $\mathbf{9 a}-\mathbf{i}$ in this study. 


\subsection{Biological Evaluation}

\subsubsection{Cytotoxic Effect of Halo-Substituted Chalcones (7a-i) and Azachalcones (9a-i)}

To investigate the cytotoxicity of halo-substituted chalcones $\mathbf{7 a}-\mathbf{i}$, azachalcones $\mathbf{9 a}-\mathbf{i}$, and synthetic natural products 1-4, the RAW 264.7 cells were treated with various concentrations of each compound for $24 \mathrm{~h}$. The viable cell numbers were assayed and compared to the control group. According to the results in Table 2, $10 \mu \mathrm{g} / \mathrm{mL}$ for each compound was chose to treat RAW 264.7 for the evaluation of anti-inflammatory activities.

Table 2. Cell viability of RAW 264.7 cells after treated with various concentrations of halo-substituted chalcones $\mathbf{7 a}-\mathbf{i}$, azachalcones $\mathbf{9 a}-\mathbf{i}$, or synthetic natural products $\mathbf{1 - 4}$ for $24 \mathrm{~h}$.

\begin{tabular}{cccccc}
\hline \multirow{2}{*}{ Compound } & \multicolumn{5}{c}{ Concentration $(\boldsymbol{\mu g} / \mathbf{m L})$} \\
\cline { 2 - 6 } & $\mathbf{0}$ & $\mathbf{1 0}$ & $\mathbf{2 5}$ & $\mathbf{5 0}$ & $\mathbf{1 0 0}$ \\
\hline $\mathbf{7 a}$ & 100.0 & $114.27 \pm 4.83$ & $99.76 \pm 18.08$ & $95.02 \pm 21.09$ & $80.32 \pm 15.54$ \\
$\mathbf{7 b}$ & 100.0 & $83.55 \pm 12.07$ & $105.08 \pm 14.37$ & $90.34 \pm 19.48$ & $55.51 \pm 4.21$ \\
$\mathbf{7 c}$ & 100.0 & $110.86 \pm 29.05$ & $115.31 \pm 15.25$ & $79.03 \pm 6.30$ & $65.77 \pm 12.03$ \\
$\mathbf{7 d}$ & 100.0 & $97.37 \pm 20.37$ & $86.35 \pm 18.47$ & $71.78 \pm 10.27$ & $34.72 \pm 4.15$ \\
$\mathbf{7 e}$ & 100.0 & $83.42 \pm 13.10$ & $69.68 \pm 5.17$ & $45.95 \pm 6.08$ & $17.24 \pm 1.29$ \\
$\mathbf{7 f}$ & 100.0 & $71.29 \pm 8.12$ & $56.92 \pm 4.88$ & $30.60 \pm 4.96$ & $19.32 \pm 2.89$ \\
$\mathbf{7 g}$ & 100.0 & $80.47 \pm 8.38$ & $75.60 \pm 12.85$ & $68.21 \pm 7.45$ & $42.19 \pm 4.87$ \\
$\mathbf{7 h}$ & 100.0 & $101.07 \pm 8.63$ & $87.16 \pm 9.03$ & $60.71 \pm 7.09$ & $16.35 \pm 0.56$ \\
$\mathbf{7 i}$ & 100.0 & $87.00 \pm 18.69$ & $64.16 \pm 6.38$ & $32.19 \pm 3.32$ & $24.23 \pm 2.00$ \\
\hline $\mathbf{9 a}$ & 100.0 & $99.00 \pm 3.19$ & $93.66 \pm 3.87$ & $70.68 \pm 2.17$ & $4.22 \pm 0.47$ \\
$\mathbf{9 b}$ & 100.0 & $123.61 \pm 0.10$ & $112.57 \pm 8.72$ & $82.18 \pm 3.87$ & $3.92 \pm 0.19$ \\
$\mathbf{9 c}$ & 100.0 & $93.28 \pm 9.09$ & $69.54 \pm 23.80$ & $14.51 \pm 2.05$ & $5.52 \pm 0.37$ \\
$\mathbf{9}$ & 100.0 & $90.39 \pm 10.15$ & $85.06 \pm 8.59$ & $63.56 \pm 3.03$ & $8.60 \pm 1.06$ \\
$\mathbf{9 f}$ & 100.0 & $102.57 \pm 16.87$ & $71.97 \pm 8.07$ & $50.11 \pm 9.90$ & $15.27 \pm 1.64$ \\
$\mathbf{9 g}$ & 100.0 & $86.56 \pm 12.35$ & $89.25 \pm 5.68$ & $34.25 \pm 3.08$ & $3.3 \pm 0.22$ \\
$\mathbf{9 h}$ & 100.0 & $84.49 \pm 8.66$ & $86.32 \pm 8.10$ & $60.61 \pm 25.05$ & $43.90 \pm 18.91$ \\
$\mathbf{9 i}$ & 100.0 & $79.14 \pm 11.53$ & $77.95 \pm 10.43$ & $67.49 \pm 8.26$ & $33.68 \pm 5.03$ \\
\hline
\end{tabular}

${ }^{1}$ The results are presented as \% of cell number of control group.

2.2.2. Effect of Halo-Substituted Chalcones (7a-i) and Azachalcones (9a-i) on mRNA and Protein Expression of Pro-Inflammatory Factors

Inflammation is one of the pathologic processes that contribute to disorders. It involves complex signal transduction pathways and the production of various pro-inflammatory factors. Mammalian toll-like receptors (TLRs) are transmembrane receptors that recognize microbial infection and trigger innate immune responses [34]. TLR4 is primarily expressed in macrophages. Binding of lipopolysaccharide (LPS) to TRL4 initiates several signal transduction pathways, including NF- $\mathrm{KB}$ [35]. NF- $k B$ is a heterodimer consisting of p65 and a p52 or p50. In cytoplasm, inactivated NF- $k B$ binds

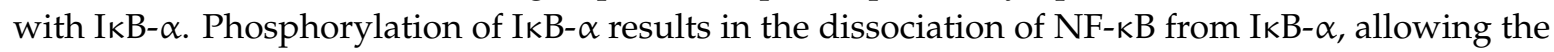
translocation of heterodimer into the nucleus and binding to the promoters of pro-inflammatory genes, such as interleukine (IL)-1 $\beta$, IL-6, tumor necrosis factor (TNF)- $\alpha$, and cyclooxygenase (COX)-2 (Figure 6). 


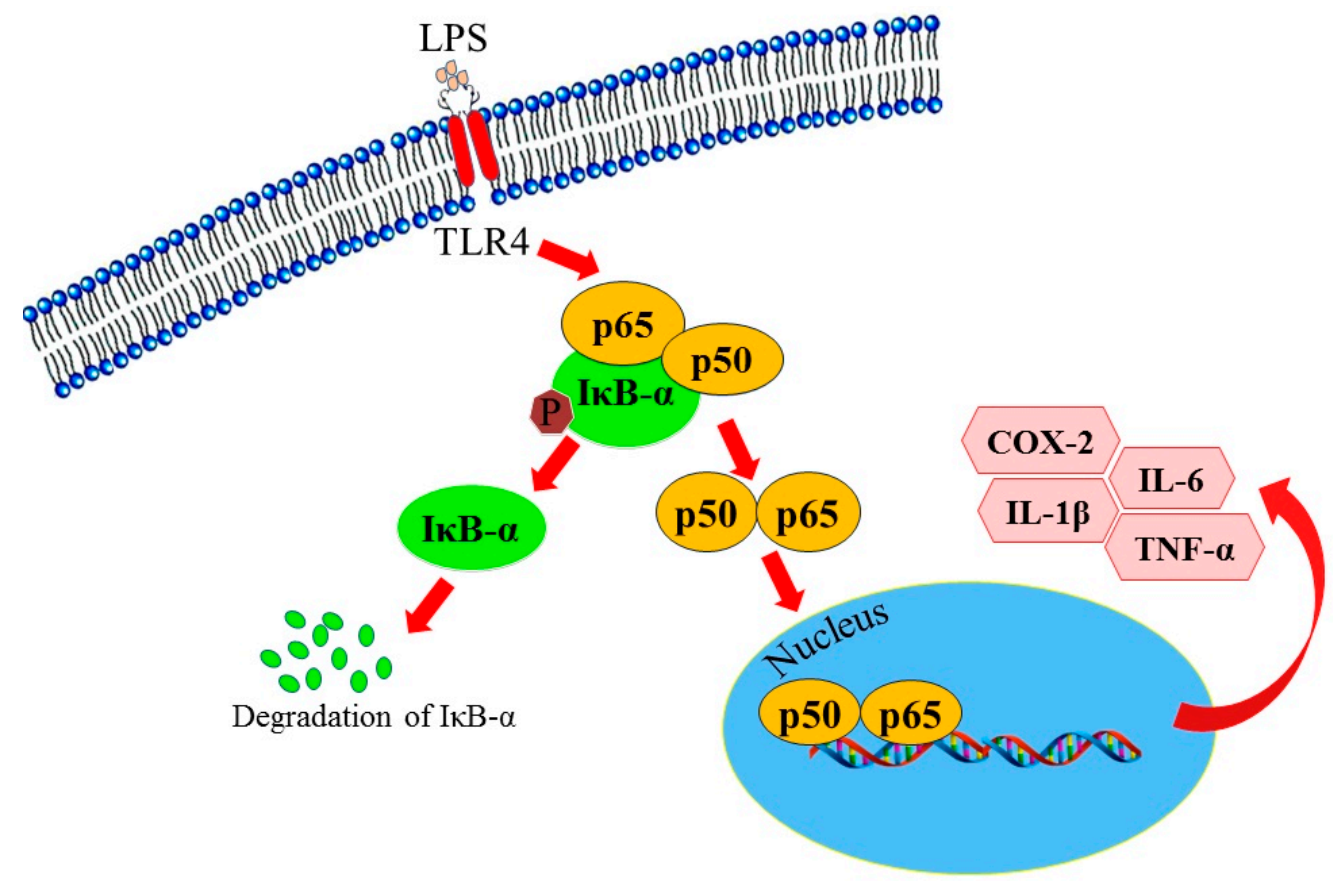

Figure 6. TLR4-mediated NF- $\kappa B$ signaling pathway.

Pre-treatment with some synthetic chalcones and azachalcones ameliorated the expression of TLR-4, IL-1 $\beta$, IL-6, TNF- $\alpha$, and COX-2 induced by LPS (Figures 7 and 8). IL-1 $\beta$, IL-6, and TNF- $\alpha$ are pro-inflammatory cytokines secreted by macrophages to initiate and regulate the progression of inflammation [36]. IL-1 $\beta$ is the master inflammatory cytokine in the IL-1 family produced at the early stages of the immune response. IL- $1 \beta$ plays a crucial role in recruitment of monocytes to the inflammation site and interactions between immune cells and nerve cells [37]. Similar to IL-1 $\beta$, IL-6 is an endogenous pyrogen that promotes fever and the production of acute phase proteins from liver. IL-6 also involves in the recruitment of immune cells to inflammation site [38]. TNF- $\alpha$ was first described for its ability to induce necrosis of tumor cells. Binding of TNF- $\alpha$ to receptors TNFR1 or TNFR2 signals NF- $\kappa B$ activation. Transcriptional induction of TNF- $\alpha$ by NF- $\kappa B$ further amplifies the signaling pathway $[39,40]$. COX catalyzes the conversion of fatty acids to prostaglandins and thromboxanes. COX-1 is constitutively expressed in all cells, but the expression of COX-2 is induced by pro-inflammatory cytokines [41]. Blocking of IL-1 $\beta$, IL-6, TNF- $\alpha$, and COX-2 has become the targeting therapy for the treatment of inflammatory diseases [42-45]. 

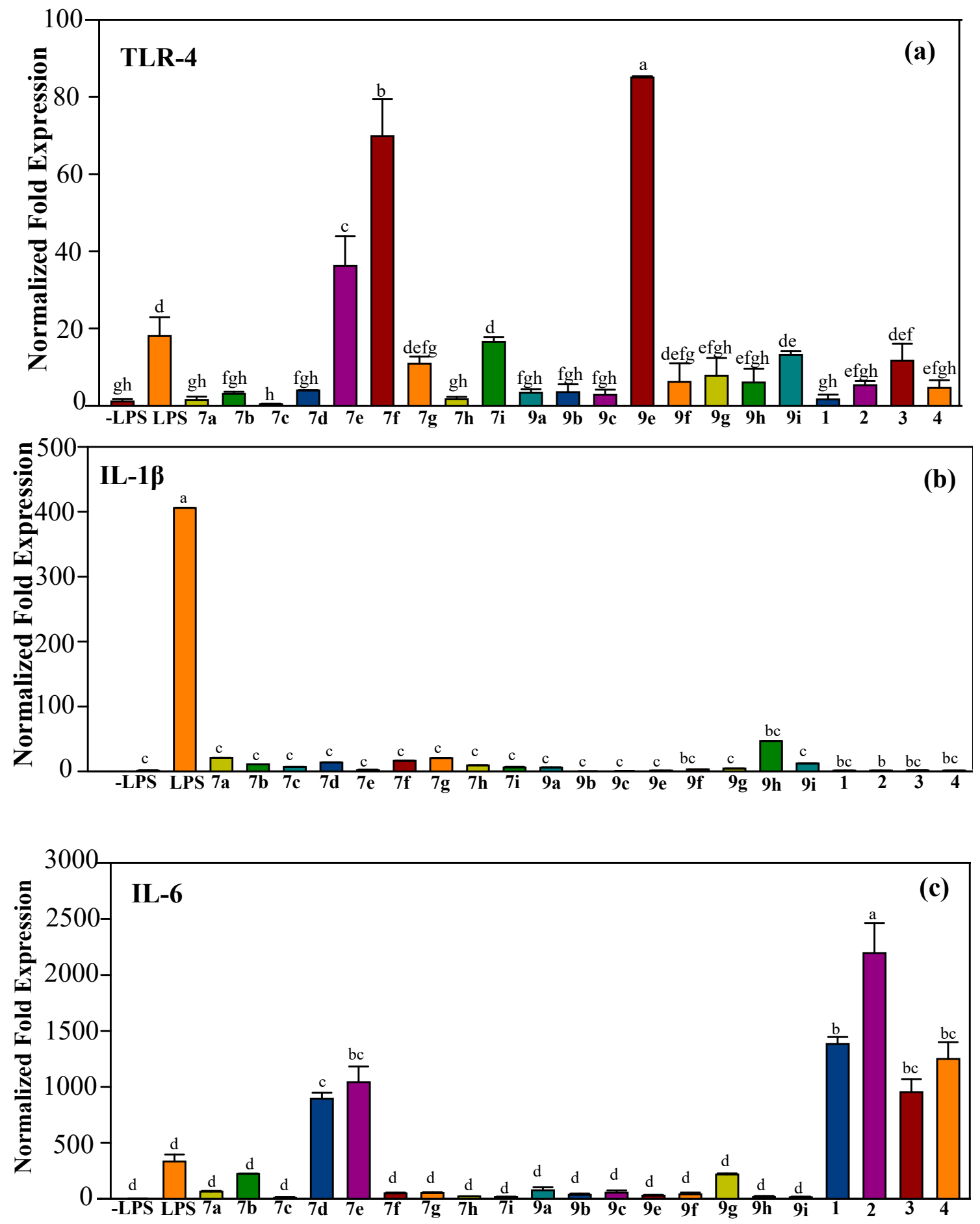

Figure 7. mRNA expression of (a) TLR-4, (b) IL-1 $\beta$, and (c) IL-6. RAW 264.7 cells were pre-treated with synthetic or natural compounds $(10 \mu \mathrm{g} / \mathrm{mL})$ for $1 \mathrm{~h}$ before induction of inflammation by LPS $(1 \mu \mathrm{g} / \mathrm{mL})$ for $6 \mathrm{~h}$. Values indicate means $\pm \mathrm{SD}$. Bars with the same letters are not significantly different $(\alpha=0.05)$. LPS: lipopolysaccharide; $7 \mathbf{a}-\mathbf{i}$ are synthetic halo-substituted chalcones; $9 \mathbf{a}-\mathbf{i}$ are synthetic halo-substituted azachalcones; $\mathbf{1 - 4}$ are synthetic natural products. 

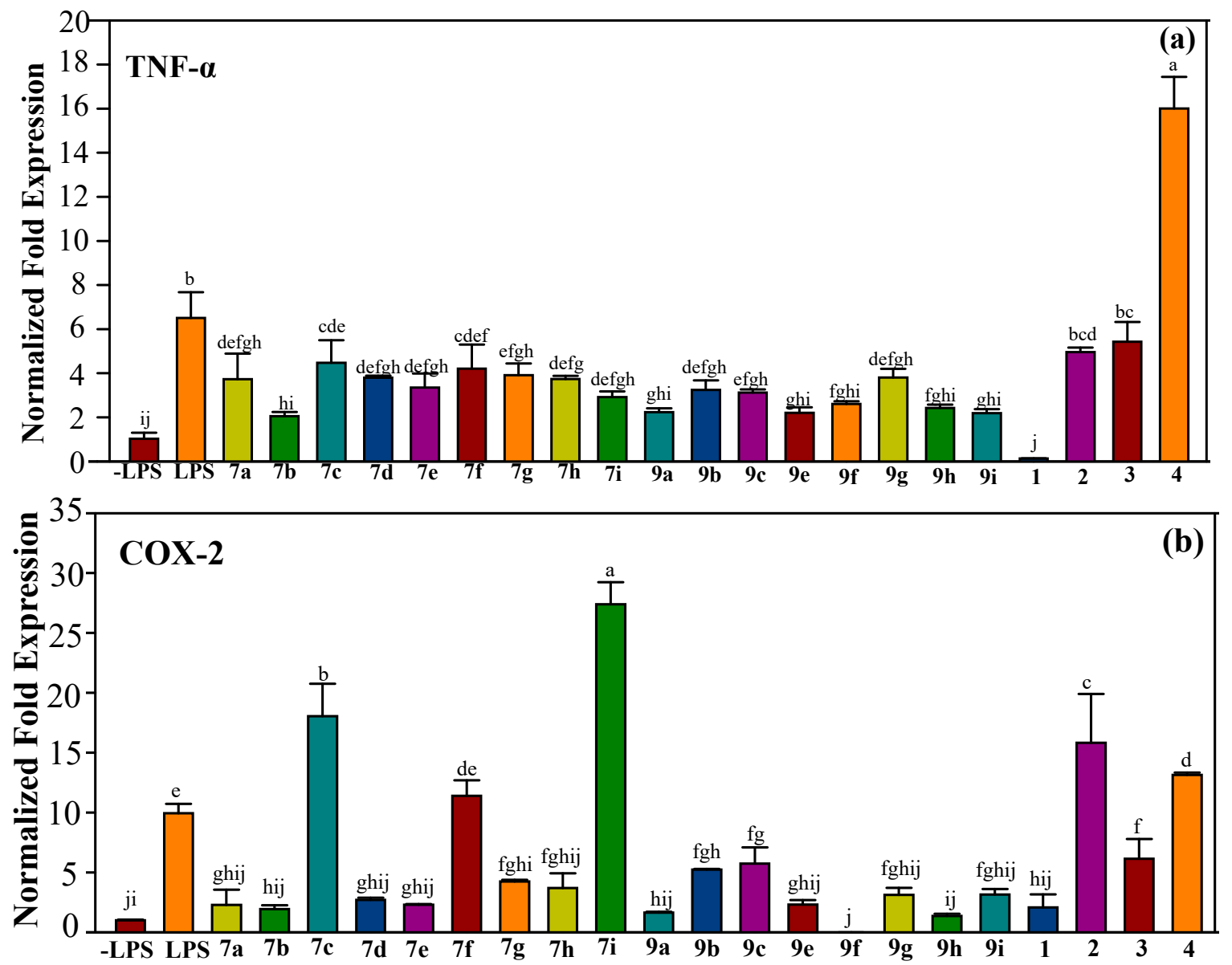

Figure 8. mRNA expression of (a) TNF- $\alpha$ and (b) COX-2. RAW 264.7 cells were pre-treated with synthetic or natural compounds $(10 \mu \mathrm{g} / \mathrm{mL})$ for $1 \mathrm{~h}$ before induction of inflammation by LPS $(1 \mu \mathrm{g} / \mathrm{mL})$ for $6 \mathrm{~h}$. Values indicate means \pm SD. Bars with the same letters are not significantly different $(\alpha=0.05)$. LPS: lipopolysaccharide; $7 \mathbf{a}-\mathbf{i}$ are synthetic halo-substituted chalcones; $9 \mathbf{9}-\mathbf{i}$ are synthetic halo-substituted azachalcones; $\mathbf{1 - 4}$ are synthetic natural products.

The anti-inflammatory effects are different among the testing compounds; however, halo-substituted azachalcones $\mathbf{9 a - i}$ showed more significant inhibition than halo-substituted chalcones $\mathbf{7 a}-\mathbf{i}$. Among the azachalcones, $\mathbf{9 a}, \mathbf{9 f}, \mathbf{9 h}$, and $\mathbf{9 i}$ showed superior anti-inflammatory activity. Therefore, protein expression of TLR4 and COX-2 was examined in RAW 264.7 cells pre-treated with 9a, 9f, 9h, or $9 \mathbf{i}$ before induction of inflammation. The results in Figure 9 show pre-treatment with these four halo-substituted azachalcones attenuated the inflammatory responses induced by LPS. Compared with the natural chalcones $\mathbf{1}$ and $\mathbf{2}$, these four synthetic compounds showed more significant inhibition on inflammation than compound $\mathbf{2}$, but not compound $\mathbf{1}$. 

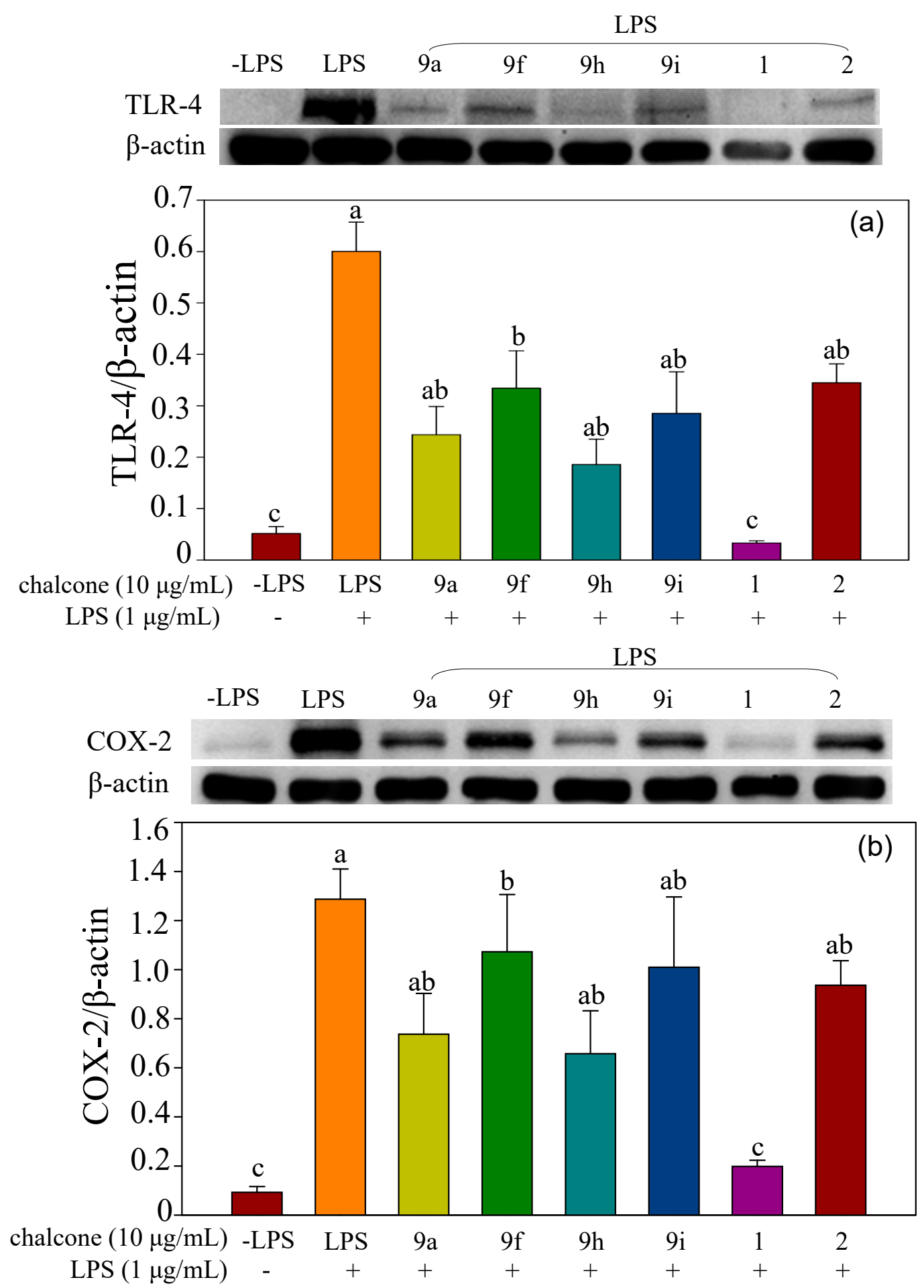

Figure 9. Protein expression of (a) TLR4 and (b) COX-2. RAW 264.7 cells were pre-treated with synthetic halo-substituted azachalcones $\mathbf{9 a}, \mathbf{9 f}, \mathbf{9 h}, \mathbf{9 i}$ or natural synthetic compounds $\mathbf{1}$ or $\mathbf{2}(10 \mu \mathrm{g} / \mathrm{mL})$ for $1 \mathrm{~h}$ before induction of inflammation by LPS $(1 \mu \mathrm{g} / \mathrm{mL})$ for $6 \mathrm{~h}$. Values indicate means $\pm \mathrm{SD}$. Bars with the same letters are not significantly different $(\alpha=0.05)$. LPS: lipopolysaccharide.

It has been reported that the electron-withdrawing groups in B-ring, as well as the electron-donating groups in A-ring on chalcone derivatives, enhanced the cytotoxic activity [30]. Since the $\mathrm{C}-2 \mathrm{OH}$ group of chalcones involved intramolecular hydrogen bonding with the carbonyl 
group, however, the C-2 nitrogen atom of azachalcones $\mathbf{9 a}-\mathbf{i}$, were to lack this attractive force. Therefore, we suspect that this difference may play a crucial role in their activity.

Based on the slight difference in structures between chalcones and azachalcones and comments on cytotoxic activity of chalcones, we intended to realize the role of hydroxyl and nitrogen atom in A ring of respective molecules. Therefore, we synthesized a series of monohalo substitutes in B ring of both chalcones $(7 \mathbf{a}-\mathbf{i})$ and azachalcone $(9 \mathbf{a}-\mathbf{i})$. This paper is the first to report the comparison of anti-inflammatory activity between synthetic halo-chalcones and -azachalcones. The results will lay the background for future development of anti-inflammatory nutraceuticals. Evaluation of bioavailability and toxicity of $\mathbf{9 a}, \mathbf{9 f}, \mathbf{9 h}$, and $\mathbf{9 i}$ halo-azachalcones is taking place in our laboratory to pioneer in vivo functional study.

\section{Materials and Methods}

Chemicals used for organic synthesis were purchased from commercial sources and used without purification except when otherwise stated. ${ }^{1} \mathrm{H}$ NMR $(600 \mathrm{MHz})$ and ${ }^{13} \mathrm{C}$ NMR $(150 \mathrm{MHz})$ spectra were recorded on a Bruker 600 instrument. Chemical shifts were reported in ppm and referenced to the residue of solvent: $\left(\mathrm{CDCl}_{3}: 7.26 \mathrm{ppm}\right.$ for ${ }^{1} \mathrm{H} ; 77.0 \mathrm{ppm}$ for $\left.{ }^{13} \mathrm{C}\right)$. Melting points were determined on Fargo MP-2D and not corrected. HRMS were recorded on Finnigan MAT-95S. Dulbecco's modified Eagle's medium (DMEM), lipopolysaccharide (LPS), and dimethyl sulfoxide (DMSO) were purchased from Sigma (St. Louis, MO, USA). Fetal bovine serum (FBS) and penicillin-streptomycin were obtained from Biowest (Kancas, MO, USA). Anti-TLR4 (rabbit anti-toll-like receptor 4 polyclonal antibody), anti-COX-2 (rabbit anti-cyclooxygenase- 2 polyclonal antibody), and anti- $\beta$-actin (mouse anti-beta actin monoclonal antibody) antibodies were purchased from Novus (Littleton, CO, USA). Peroxidase-conjugated sheep anti-mouse IgG and goat anti-rabbit IgG were obtained from Jackson ImmunoResearch (West Grove, PA, USA).

\subsection{General Procedure of Claisen-Schmidt Condensation in Synthesis of $\mathbf{7 a - i}$}

To a stirred solution of $5(0.100 \mathrm{~mL}, 0.108 \mathrm{~g}$, and $0.890 \mathrm{mmol})$, for example, EtOH $(2.5 \mathrm{~mL})$ was added the three equivalents of $8 \mathrm{M} \mathrm{KOH}$. This mixture was stirred at $0{ }^{\circ} \mathrm{C}$ for $10 \mathrm{~min}$, followed by addition of the corresponding aldehyde (1.5 equiv.) at that temperature. The mixture was gradually warmed up to room temperature until 5 was consumed by TLC detection. At the end of reaction time, the mixture was neutralized with $2 \mathrm{~N} \mathrm{HCl}$, diluted with $\mathrm{H}_{2} \mathrm{O}$, and extracted with $\mathrm{CH}_{2} \mathrm{Cl}_{2}$. The organic layer was dried over $\mathrm{MgSO}_{4}$ and purified by flash column chromatography.

\subsection{1. (E)-3-(4-Fluorophenyl)-1-(2-hydroxyphenyl)prop-2-en-1-one (7a)}

Purification by flash column chromatography $\left(\mathrm{CH}_{2} \mathrm{Cl}_{2}:\right.$ Hexanes = 1:5-1:3). m.p. $118-120{ }^{\circ} \mathrm{C}$ (lit. [29] 120-122 $\left.{ }^{\circ} \mathrm{C}\right)$. Yellow solid. ${ }^{1} \mathrm{H}$ NMR (600 MHz, $\left.\mathrm{CDCl}_{3}\right) \delta 12.79(\mathrm{~s}, 1 \mathrm{H}), 7.90(\mathrm{~d}, J=8.0 \mathrm{~Hz}, 1 \mathrm{H})$, $7.88(\mathrm{~d}, J=15.5 \mathrm{~Hz}, 1 \mathrm{H}), 7.66(\mathrm{~d}, J=5.6 \mathrm{~Hz}, 1 \mathrm{H}), 7.65(\mathrm{~d}, J=5.6 \mathrm{~Hz}, 1 \mathrm{H}), 7.58(\mathrm{~d}, J=15.5 \mathrm{~Hz}, 1 \mathrm{H})$, $7.50(\mathrm{t}, J=8.2 \mathrm{~Hz}, 1 \mathrm{H}), 7.13(\mathrm{~d}, J=8.5 \mathrm{~Hz}, 1 \mathrm{H}), 7.12(\mathrm{~d}, J=8.5 \mathrm{~Hz}, 1 \mathrm{H}), 7.03(\mathrm{~d}, J=8.5 \mathrm{~Hz}, 1 \mathrm{H}), 6.94$ $(\mathrm{t}, J=7.4 \mathrm{~Hz}, 1 \mathrm{H}) .{ }^{13} \mathrm{C}$ NMR $\left(150 \mathrm{MHz}, \mathrm{CDCl}_{3}\right) \delta 193.5,164.2\left({ }^{1} \mathrm{~J}=251 \mathrm{~Hz}\right), 163.6,140.1,136.4,130.8$ $\left({ }^{4} J=1.5 \mathrm{~Hz}\right), 130.6\left({ }^{3} \mathrm{~J}=7.5 \mathrm{~Hz}\right)(\times 2), 129.6,119.9,119.8,118.9,118.6,116.3,116.2\left({ }^{2} J=22.5 \mathrm{~Hz}\right)(\times 2)$. HRMS (ESI) calculated for $\mathrm{C}_{15} \mathrm{H}_{12} \mathrm{FO}_{2}[\mathrm{M}+\mathrm{H}]^{+}$243.0821. Found: 243.0823.

\subsection{2. (E)-3-(4-Chlorophenyl)-1-(2-hydroxyphenyl)prop-2-en-1-one (7b)}

Purification by flash column chromatography $\left(\mathrm{CH}_{2} \mathrm{Cl}_{2}\right.$ :Hexanes $\left.=1: 5-1: 3\right)$. m.p. $152-154{ }^{\circ} \mathrm{C}$ (lit. [29] 143-145 $\left.{ }^{\circ} \mathrm{C}\right)$. Yellow solid. ${ }^{1} \mathrm{H}$ NMR $\left(600 \mathrm{MHz}, \mathrm{CDCl}_{3}\right) \delta 12.75(\mathrm{~s}, 1 \mathrm{H}), 8.00(\mathrm{~d}, J=15.7 \mathrm{~Hz}, 1 \mathrm{H})$, $7.92(\mathrm{dd}, J=8.2,1.7 \mathrm{~Hz}, 1 \mathrm{H}), 7.79(\mathrm{~d}, J=15.7 \mathrm{~Hz}, 1 \mathrm{H}), 7.66(\mathrm{td}, J=7.6,1.7 \mathrm{~Hz}, 1 \mathrm{H}), 7.51(\mathrm{ddd}, J=8.5$, $7.2,1.6 \mathrm{~Hz}, 1 \mathrm{H}), 7.44-7.39(\mathrm{~m}, 1 \mathrm{H}), 7.22(\mathrm{td}, J=7.6,1.0 \mathrm{~Hz}, 1 \mathrm{H}), 7.16(\mathrm{ddd}, J=9.2,8.2,0.9 \mathrm{~Hz}, 1 \mathrm{H}), 7.04$ $(\mathrm{dd}, J=8.5,1.0 \mathrm{~Hz}, 1 \mathrm{H}), 6.96(\mathrm{td}, J=7.5,1.1 \mathrm{~Hz}, 1 \mathrm{H}) .{ }^{13} \mathrm{C} \mathrm{NMR}\left(150 \mathrm{MHz}, \mathrm{CDCl}_{3}\right) \delta 193.8,163.7,162.8$, $161.1,138.3,136.5,132.2,130.2,129.8,124.6,122.9,120.0,118.9,118.7,116.4$. HRMS (ESI) calculated for $\mathrm{C}_{15} \mathrm{H}_{12} \mathrm{ClO}_{2}[\mathrm{M}]^{+}$259.0526. Found: 259.0530. 


\subsection{3. (E)-3-(4-Bromophenyl)-1-(2-hydroxyphenyl)prop-2-en-1-one (7c)}

Purification by flash column chromatography $\left(\mathrm{CH}_{2} \mathrm{Cl}_{2}\right.$ :Hexanes $\left.=1: 3-1: 2\right)$. m.p. $145-148{ }^{\circ} \mathrm{C}$. (lit. [29] 150-152 $\left.{ }^{\circ} \mathrm{C}\right)$. Yellow solid. ${ }^{1} \mathrm{H}$ NMR (600 MHz, $\left.\mathrm{CDCl}_{3}\right) \delta 12.73(\mathrm{~s}, 1 \mathrm{H}), 7.91(\mathrm{~d}, \mathrm{~J}=8.0 \mathrm{~Hz}$, $1 \mathrm{H}), 7.85(\mathrm{~d}, J=15.5 \mathrm{~Hz}, 1 \mathrm{H}), 7.65(\mathrm{~d}, J=15.5 \mathrm{~Hz}, 1 \mathrm{H}), 7.58(\mathrm{~d}, J=8.3 \mathrm{~Hz}, 2 \mathrm{H}), 7.55-7.49(\mathrm{~m}, 3 \mathrm{H}), 7.04$ $(\mathrm{d}, J=8.3 \mathrm{~Hz}, 1 \mathrm{H}), 6.95(\mathrm{t}, J=7.3 \mathrm{~Hz}, 1 \mathrm{H}) .{ }^{13} \mathrm{C} \mathrm{NMR}\left(150 \mathrm{MHz}, \mathrm{CDCl}_{3}\right)$ 193.5, 163.6, 144.0, 136.6, 133.5, $132.3,130.0$ (x3), 129.6, 125.3, 120.7, 119.9, 118.9, 118.7. HRMS (ESI) calculated for $\mathrm{C}_{15} \mathrm{H}_{12} \mathrm{BrO}_{2}[\mathrm{M}+\mathrm{H}]^{+}$ 303.0021. Found: 303.0025 .

\subsection{4. (E)-3-(3-Fluorophenyl)-1-(2-hydroxyphenyl)prop-2-en-1-one (7d)}

Purification by flash column chromatography $\left(\mathrm{CH}_{2} \mathrm{Cl}_{2}\right.$ :Hexanes = 1:8-1:6). m.p. $100-101{ }^{\circ} \mathrm{C}$ (lit. [29] 109-110 $\left.{ }^{\circ} \mathrm{C}\right)$. Yellow solid. ${ }^{1} \mathrm{H}$ NMR (600 MHz, $\left.\mathrm{CDCl}_{3}\right) \delta 12.70(\mathrm{~s}, 1 \mathrm{H}), 7.91(\mathrm{~d}, \mathrm{~J}=8.1 \mathrm{~Hz}$, $1 \mathrm{H}), 7.86(\mathrm{~d}, J=15.4 \mathrm{~Hz}, 1 \mathrm{H}), 7.64(\mathrm{~d}, J=15.4 \mathrm{~Hz}, 1 \mathrm{H}), 7.52(\mathrm{t}, J=7.7 \mathrm{~Hz}, 1 \mathrm{H}), 7.44-7.40(\mathrm{~m}, 2 \mathrm{H}), 7.36$ $(\mathrm{d}, J=9.6 \mathrm{~Hz}, 1 \mathrm{H}), 7.14(\mathrm{t}, J=7.8 \mathrm{~Hz}, 1 \mathrm{H}), 7.04(\mathrm{t}, J=8.3 \mathrm{~Hz}, 1 \mathrm{H}), 6.96(\mathrm{t}, J=7.4 \mathrm{~Hz}, 1 \mathrm{H}) .{ }^{13} \mathrm{C} \mathrm{NMR}$ $\left(150 \mathrm{MHz} \mathrm{CDCl}_{3}\right) \delta 193.4,163.6,163.0\left({ }^{1} \mathrm{~J}=246 \mathrm{~Hz}\right), 143.9,136.9,136.7\left({ }^{2} \mathrm{~J}=33 \mathrm{~Hz}\right), 130.6\left({ }^{3} \mathrm{~J}=9 \mathrm{~Hz}\right)$, 129.6, 124.7, 121.4, $119.9(\times 3), 118.8\left({ }^{2} \mathrm{~J}=36 \mathrm{~Hz}\right), 117.7\left({ }^{2} \mathrm{~J}=21 \mathrm{~Hz}\right), 114.6\left({ }^{2} \mathrm{~J}=21 \mathrm{~Hz}\right)$. HRMS (ESI) calculated for $\mathrm{C}_{15} \mathrm{H}_{12} \mathrm{FO}_{2}[\mathrm{M}+\mathrm{H}]^{+}$243.0821. Found: 243.0825 .

\subsection{5. (E)-3-(3-Chlorophenyl)-1-(2-hydroxyphenyl)prop-2-en-1-one (7e)}

Purification by flash column chromatography $\left(\mathrm{CH}_{2} \mathrm{Cl}_{2}\right.$ :Hexanes = 1:5-1:3). m.p. $106-108{ }^{\circ} \mathrm{C}$ (lit. [29] 105-107 $\left.{ }^{\circ} \mathrm{C}\right)$. Yellow-orange solid. ${ }^{1} \mathrm{H}$ NMR $\left(600 \mathrm{MHz}, \mathrm{CDCl}_{3}\right) \delta 12.71(\mathrm{~s}, 1 \mathrm{H}), 7.91(\mathrm{~d}, J=8.0 \mathrm{~Hz}$, $1 \mathrm{H}), 7.83(\mathrm{~d}, J=15.5 \mathrm{~Hz}, 1 \mathrm{H}), 7.65(\mathrm{~s}, 1 \mathrm{H}), 7.63(\mathrm{~d}, J=15.1 \mathrm{~Hz}, 1 \mathrm{H}), 7.52-7.49(\mathrm{~m}, 2 \mathrm{H}), 7.40(\mathrm{t}, J=7.9 \mathrm{~Hz}$, $1 \mathrm{H}), 7.37(\mathrm{t}, J=7.9 \mathrm{~Hz}, 1 \mathrm{H}), 7.03(\mathrm{~d}, J=8.4 \mathrm{~Hz}, 1 \mathrm{H}), 6.96(\mathrm{t}, J=7.6 \mathrm{~Hz}, 1 \mathrm{H}) .{ }^{13} \mathrm{C} \mathrm{NMR}\left(150 \mathrm{MHz}, \mathrm{CDCl}_{3}\right)$ $\delta$ 193.4, 163.6, 143.6, 136.6, 136.4, 135.1, 130.7, 130.3, 129.7, 128.0, 127.0, 121.5, 119.9, 118.9, 118.7. HRMS (ESI) calculated for $\mathrm{C}_{15} \mathrm{H}_{12} \mathrm{ClO}_{2}[\mathrm{M}]^{+}$259.0526. Found: 259.0523 .

\subsection{6. (E)-3-(3-Bromophenyl)-1-(2-hydroxyphenyl)prop-2-en-1-one (7f)}

Purification by flash column chromatography $\left(\mathrm{CH}_{2} \mathrm{Cl}_{2}:\right.$ Hexanes $\left.=1: 5-1: 3\right)$. m.p. $98-100{ }^{\circ} \mathrm{C}$ (lit. [29] 108-110 $\left.{ }^{\circ} \mathrm{C}\right)$. Yellow solid. ${ }^{1} \mathrm{H}$ NMR (600 MHz, $\left.\mathrm{CDCl}_{3}\right) \delta 12.70(\mathrm{~s}, 1 \mathrm{H}), 7.92(\mathrm{~d}, J=8.0 \mathrm{~Hz}, 1 \mathrm{H})$, $7.83(\mathrm{~d}, J=15.5 \mathrm{~Hz}, 1 \mathrm{H}), 7.82(\mathrm{~s}, 1 \mathrm{H}), 7.64(\mathrm{~d}, J=15.5 \mathrm{~Hz}, 1 \mathrm{H}), 7.56(\mathrm{~d}, J=7.6 \mathrm{~Hz}, 2 \mathrm{H}), 7.52(\mathrm{t}, J=7.5 \mathrm{~Hz}$, $1 \mathrm{H}), 7.32(\mathrm{t}, J=7.9 \mathrm{~Hz}, 1 \mathrm{H}), 7.04(\mathrm{~d}, J=8.3 \mathrm{~Hz}, 1 \mathrm{H}), 6.96(\mathrm{t}, J=7.4 \mathrm{~Hz}, 1 \mathrm{H}) .{ }^{13} \mathrm{C} \mathrm{NMR}\left(150 \mathrm{MHz}, \mathrm{CDCl}_{3}\right)$ $\delta$ 193.4, 163.7, 143.6, 136.7 (x2), 133.6, 131.0, 130.5, 129.7, 127.5, 123.2, 121.5, 119.9, 119.0, 118.7. HRMS (ESI) calculated for $\mathrm{C}_{15} \mathrm{H}_{12} \mathrm{BrO}_{2}[\mathrm{M}+\mathrm{H}]^{+}$303.0021. Found: 303.0023.

\subsection{7. (E)-3-(2-Fluorophenyl)-1-(2-hydroxyphenyl)prop-2-en-1-one (7g)}

Purification by flash column chromatography $\left(\mathrm{CH}_{2} \mathrm{Cl}_{2}\right.$ :Hexanes = 1:4-1:3). m.p. 90-93 ${ }^{\circ} \mathrm{C}$ (lit. [46] $\left.80{ }^{\circ} \mathrm{C}\right)$. Yellow solid. ${ }^{1} \mathrm{H} \mathrm{NMR}\left(600 \mathrm{MHz}, \mathrm{CDCl}_{3}\right) \delta 12.76(\mathrm{~s}, 1 \mathrm{H}), 7.91(\mathrm{~d}, J=8.1 \mathrm{~Hz}, 1 \mathrm{H}), 7.78(\mathrm{~d}$, $J=15.7 \mathrm{~Hz}, 1 \mathrm{H}), 7.65(\mathrm{t}, J=7.5 \mathrm{~Hz}, 1 \mathrm{H}), 7.51(\mathrm{t}, J=7.3 \mathrm{~Hz}, 1 \mathrm{H}), 7.41(\mathrm{dd}, J=13.6,6.4 \mathrm{~Hz}, 1 \mathrm{H}), 7.22$ $(\mathrm{t}, J=7.6 \mathrm{~Hz}, 1 \mathrm{H}), 7.15(\mathrm{dd}, J=10.6,8.6 \mathrm{~Hz}, 1 \mathrm{H}), 7.03(\mathrm{~d}, J=8.3 \mathrm{~Hz}, 1 \mathrm{H}), 6.95(\mathrm{t}, J=7.6 \mathrm{~Hz}, 1 \mathrm{H}) .{ }^{13} \mathrm{C}$ NMR $\left(150 \mathrm{MHz} \mathrm{CDCl}_{3}\right) \delta 193.8,163.6,161.9\left({ }^{1} \mathrm{~J}=254.0 \mathrm{~Hz}\right), 138.2,136.5,132.2\left({ }^{3} \mathrm{~J}=8.8 \mathrm{~Hz}\right), 130.1$, $129.7,124.5\left({ }^{4} J=3.0 \mathrm{~Hz}\right), 122.8\left({ }^{3} \mathrm{~J}=7.9 \mathrm{~Hz}\right), 122.7,120.0,118.9,118.6,116.4\left({ }^{2} \mathrm{~J}=23.0 \mathrm{~Hz}\right)$. HRMS (ESI) calculated for $\mathrm{C}_{15} \mathrm{H}_{12} \mathrm{FO}_{2}[\mathrm{M}+\mathrm{H}]^{+}$242.0821. Found: 243.0825 .

\subsection{8. (E)-3-(2-Chlorophenyl)-1-(2-hydroxyphenyl)prop-2-en-1-one (7h)}

Purification by flash column chromatography $\left(\mathrm{CH}_{2} \mathrm{Cl}_{2}\right.$ :Hexanes =1:3-1:2). m.p. $103-105{ }^{\circ} \mathrm{C}$ (lit. [47] 138-140 $\left.{ }^{\circ} \mathrm{C}\right)$.Yellow solid. ${ }^{1} \mathrm{H}$ NMR $\left(600 \mathrm{MHz}, \mathrm{CDCl}_{3}\right) \delta 12.72(\mathrm{~s}, 1 \mathrm{H}), 8.31(\mathrm{~d}, \mathrm{~J}=15.6 \mathrm{~Hz}, 1 \mathrm{H})$, $7.91(\mathrm{~d}, J=8.0 \mathrm{~Hz}, 1 \mathrm{H}), 7.77(\mathrm{dd}, J=7.6,1.3 \mathrm{~Hz}, 1 \mathrm{H}), 7.65(\mathrm{~d}, J=15.5 \mathrm{~Hz}, 1 \mathrm{H}), 7.52(\mathrm{t}, J=7.3 \mathrm{~Hz}, 1 \mathrm{H})$, $7.47(\mathrm{~d}, J=7.7 \mathrm{~Hz}, 1 \mathrm{H}), 7.36(\mathrm{td}, J=8.1,2.1 \mathrm{~Hz}, 1 \mathrm{H}), 7.34(\mathrm{t}, J=6.9 \mathrm{~Hz}, 1 \mathrm{H}), 7.04(\mathrm{~d}, J=8.3 \mathrm{~Hz}, 1 \mathrm{H}), 6.95$ $(\mathrm{t}, J=7.9 \mathrm{~Hz}, 1 \mathrm{H}) .{ }^{13} \mathrm{C}$ NMR $\left(150 \mathrm{MHz}, \mathrm{CDCl}_{3}\right) \delta 193.6,163.7,141.2,136.5,135.8,133.0,131.5,130.4$, 
129.7, 128.0, 127.1, 122.9, 119.9, 118.9, 118.7. HRMS (ESI) calculated for $\mathrm{C}_{15} \mathrm{H}_{12} \mathrm{ClO}_{2}[\mathrm{M}+\mathrm{H}]^{+} 259.0526$. Found: 259.0527.

\subsection{9. (E)-3-(2-Bromophenyl)-1-(2-hydroxyphenyl)prop-2-en-1-one (7i)}

Purification by flash column chromatography $\left(\mathrm{CH}_{2} \mathrm{Cl}_{2}:\right.$ Hexanes $\left.=1: 4-1: 3\right)$. m.p. $103-105{ }^{\circ} \mathrm{C}$ (lit. [48] 103-104 $\left.{ }^{\circ} \mathrm{C}\right)$. Yellow solid. ${ }^{1} \mathrm{H}$ NMR $\left(600 \mathrm{MHz}, \mathrm{CDCl}_{3}\right) \delta 12.71(\mathrm{~s}, 1 \mathrm{H}), 8.26(\mathrm{~d}, J=15.6 \mathrm{~Hz}$, $1 \mathrm{H}), 7.90(\mathrm{~d}, J=8.0 \mathrm{~Hz}, 1 \mathrm{H}), 7.75(\mathrm{~d}, J=7.8 \mathrm{~Hz}, 1 \mathrm{H}), 7.66(\mathrm{~d}, J=8.0 \mathrm{~Hz}, 1 \mathrm{H}), 7.59(\mathrm{~d}, J=15.4 \mathrm{~Hz}, 1 \mathrm{H})$, $7.51(\mathrm{td}, J=8.3,1.1 \mathrm{~Hz}, 1 \mathrm{H}), 7.38(\mathrm{t}, J=7.4 \mathrm{~Hz}, 1 \mathrm{H}), 7.27(\mathrm{td}, J=7.6,1.6 \mathrm{~Hz}, 1 \mathrm{H}), 7.04(\mathrm{~d}, J=8.3 \mathrm{~Hz}$, $1 \mathrm{H}), 6.95(\mathrm{t}, J=7.3 \mathrm{~Hz}, 1 \mathrm{H}) .{ }^{13} \mathrm{C} \mathrm{NMR}\left(150 \mathrm{MHz}, \mathrm{CDCl}_{3}\right) \delta 193.6,163.6,143.7,136.6,134.8,133.7,131.6$, 129.7, 127.8, 126.1, 123.0, 119.9, 118.9, 118.7. HRMS (ESI) calculated for $\mathrm{C}_{15} \mathrm{H}_{12} \mathrm{BrO}_{2}[\mathrm{M}+\mathrm{H}]^{+} 303.0021$. Found: 303.0019 .

\subsection{Biological Evaluation}

\subsubsection{Cell Culture}

Mouse BALB/c macrophage cell line RAW 264.7, which was obtained from Biosource Collection and Research Center of Food Industry Research and Development Institute (Shinchu, Taiwan), was cultured in DMEM supplemented with FBS $(10 \%)$, sodium bicarbonate $(0.22 \%)$, streptomycin (100 units $/ \mathrm{mL}$ ), and penicillin ( 100 units $/ \mathrm{mL}$ ) in a $37^{\circ} \mathrm{C}$ incubator with $5 \% \mathrm{CO}_{2}$. When $50 \%$ confluence was reached, the cells were cultured with various synthetic chalcones for $1 \mathrm{~h}$ before LPS was added to the medium (final concentration $1 \mu \mathrm{g} / \mathrm{mL}$ ) to induce inflammation. Six hours later, the cells were harvested for real-time PCR analysis and immunoblot analysis [49].

\subsubsection{Cell Viability Assay}

RAW 264.7 cells were seeded in 96-well plate at a concentration of $3 \times 10^{5} /$ well. Twenty-four hours after seeding, the cells were treated with various concentrations of synthetic chalcones and LPS $(1 \mu \mathrm{g} / \mathrm{mL})$ for another $24 \mathrm{~h}$ before the medium was removed and the cells were cultured with new medium containing MTT (3-(4,5-dimethylthiazol-2-yl)-2,5-diphenyltetrazolium bromide) at a final concentration of $0.5 \mathrm{mg} / \mathrm{mL}$. Four hours later, the purple formazan was dissolved by DMSO, and the absorbance at $570 \mathrm{~nm}$ was taken. The absorbance is proportional to the viability of cells [49].

\subsubsection{Quantitative Real-Time PCR Analysis}

Effects of synthetic chalcones on the expressions of following genes were quantified: signal recognition particle 72 (SRP 72), IKB- $\alpha$, cycloxygenase-2 (COX-2), interleukin-6 (IL-6), interleukin- $\beta$ (IL-1 $\beta$ ), tumor necrosis factor- $\alpha(\mathrm{TNF}-\alpha)$, and inducible nitric oxide synthase (iNOS). Total RNA was extracted from the cells by using Aurum ${ }^{\mathrm{TM}}$ Total RNA MiniKit (BIO-RAD, Hercules, CA, USA). Complementary DNA (cDNA) was synthesized by using iScript ${ }^{\mathrm{TM}}$ cDNA Synthesis Kit (BIO-RAD, Hercules, CA, USA) and performed on T3 Thermocycler (Biometra, Germany) with the program of $25{ }^{\circ} \mathrm{C}$ for $5 \mathrm{~min}, 42{ }^{\circ} \mathrm{C}$ for $30 \mathrm{~min}$, and $85{ }^{\circ} \mathrm{C}$ for $5 \mathrm{~min}$. The cDNA $(5 \mathrm{ng} / \mu \mathrm{L})$ was mixed with SYBR green (iQ ${ }^{\mathrm{TM}}$ SYBR Green Supermix, BIO-RAD, Hercules, CA, USA) and primers (Table 3). The mixture was subject to the thermal cycling under the following conditions: heating up to $95^{\circ} \mathrm{C}$ in $3 \mathrm{~min}$, followed by 40 cycles at $95^{\circ} \mathrm{C}$ for $10 \mathrm{~s}$ and $50^{\circ} \mathrm{C}$ for $30 \mathrm{~s}$. The expression of each gene was normalized to the corresponding SRP 72 (internal reference) threshold cycle (ct) values by the $2^{-\Delta \Delta c t}$ method [50]. 
Table 3. Forward and reverse primers.

\begin{tabular}{ccc}
\hline Gene & Forward Primer $\mathbf{5}^{\prime} \mathbf{3}^{\prime}$ & ${\text { Reverse Primer } \mathbf{5}^{\prime} \mathbf{3}^{\prime}}^{\prime}$ \\
\hline SRP72 & CACACCCTAGCCCAACTTATT & TCAAGCGCCTCAACATCTAC \\
$T L R 4$ & TTCAGAACTTCAGTGGCTGGATTTA & GTCTCCACAGCCACCAGATTCTC \\
$I \kappa B-\alpha$ & CCTTCCTCAACTTCCAGAACAA & GATCACAGCCAGCTTTCAGA \\
$p 65$ & TGTGGAGATCATCGAACAGCCGAA & TGTTCCTGGTCCTGTGTAGCCATT \\
$I L-1 \beta$ & GTTACATCAGCACCTCACAA & TTAGAAACAGCTCAGCCCATAC \\
$I L-6$ & CTTCCATCCAGTTGCCTTCT & CTCCGACTTGTGAAGTGGTATAG \\
TNF- $\alpha$ & TTGTCTACTCCCAGGTTCTCT & GAGGTTGACTTTCTCCTGGTATG \\
$C O X-2$ & CGGACTGGATTCTATGGTGAAA & CTTGAAGTGGGTCAGGATGTAG \\
\hline
\end{tabular}

\subsubsection{Immunoblot Analysis}

Cells were harvested and resuspended in lysis buffer containing $50 \mathrm{mM}$ Tris- $\mathrm{HCl}, 1 \%$ Noniswr P40, and $150 \mathrm{mM}$ sodium chloride before centrifuged at $10,000 \times g$ for $30 \mathrm{~min}$. Proteins in supernatant were separated by sodium dodecyl sulfate polyacrylamide gel electrophoresis (SDS-PAGE) and transferred to polyvinylidene fluoride (PVDF) membrane (PerkinElmer, Waltham, MA, USA). Five percent stacking gel and $8 \%$ separating gel were used for SDS-PAGE. The membranes were blocked with $5 \%$ nonfat dry milk in Tris-buffered saline containing Tween (TBST) $(20 \mathrm{mM}$ Tris- $\mathrm{HCl}, 137 \mathrm{mM} \mathrm{NaCl}, 0.1 \%$ Tween-20, $\mathrm{pH}$ 8.3) for one hour before being incubated with primary antibody (anti-TLR4, anti-COX-2, or anti- $\beta$-actin) overnight at $4{ }^{\circ} \mathrm{C}$ and horseradish peroxidase-conjugated secondary antibody for $1 \mathrm{~h}$ at room temperature. An enhanced chemiluminescence kit (ECL, PerkinElmer, Waltham, MA, USA) was applied to detect the immunoreactive proteins [49].

\section{Conclusions}

A series of monohalo-substituted chalcones and azachalcones were synthesized and compared their anti-inflammatory activity with a concentration of $10 \mu \mathrm{g} / \mathrm{mL}$. In this series, azachalcones exerted more significant activity than chalcones on inhibition of pro-inflammatory factor expression, including TLR4, IKB- $\alpha$, p65, IL-1 $\beta$, IL-6, TNF- $\alpha$, and COX-2. In lack of the internal hydrogen bonding between $\mathrm{C}-2$ hydroxy group and carbonyl group as in chalcones, our results indicate that the nitrogen atom in azachalcones might be important to contribute their activity. Therefore, azachalcones $\mathbf{9 a}, \mathbf{9 f}, \mathbf{9 h}$, and $\mathbf{9 i}$ used for further investigation is undergoing in our laboratory.

Supplementary Materials: The following are available online. The ${ }^{1} \mathrm{H}$ and ${ }^{13} \mathrm{C}$ NMR data for compounds $7 \mathbf{a}-\mathbf{i}$ and $9 \mathbf{a}-\mathbf{i}$.

Acknowledgments: We gratefully acknowledge the Ministry of Science and Technology (MOST 104-2113-M-032-002), Tamkang University, and Shih Chien University for supporting this work.

Author Contributions: Tzenge-Lien Shih conceived and designed the experiments; Chia-Wai Li performed the synthesis of compounds 7a-i and 9a-i; Ming-Hwa Liu performed the biological experiments. Chia-Feng Kuo drsigned the biological experiments, analyzed the data, and wrote the manuscript.

Conflicts of Interest: The authors declare no conflicts of interest.

\section{References}

1. Rakoff-Nahoum, S. Why cancer and inflammation. Yale J. Biol. Med. 2006, 79, 123-130. [PubMed]

2. Monteiro, R.; Azevedo, I. Chronic inflammation in obesity and the metabolic syndrome. Med. Inflamm. 2010, 2010, 289645. [CrossRef] [PubMed]

3. Donath, M.Y.; Shoelson, S.E. Type 2 diabetes as an inflammatory disease. Nat. Rev. Immunol. 2011, 11, 98-107. [CrossRef] [PubMed]

4. Tuttolomondo, A.; Di Raimondo, D.; Pecoraro, R.; Arnao, V.; Pinto, A.; Licata, G. Atherosclerosis as an inflammatory disease. Curr. Pharm. Des. 2012, 18, 4266-4288. [CrossRef] [PubMed]

5. Maiuri, A.R.; O'Hagan, H.M. Interplay between inflammation and epigenetic changes in cancer. Prog. Mol. Biol. Transl. Sci. 2016, 144, 69-117. [PubMed] 
6. Kim, Y.-J.; Ko, H.; Park, J.-S.; Han, I.-H.; Amor, E.C.; Lee, J.W.; Yang, H.O. Dimethyl cardamonin inhibits lipopolysaccharide-induced inflammatory factors through blocking NF- $\mathrm{B}$ p65 activation. Int. Immunopharmacol. 2010, 10, 1127-1134. [CrossRef] [PubMed]

7. Orlikova, B.; Tasdemir, D.; Golais, F.; Dicato, M.; Diederich, M. Dietary chalcones with chemopreventive and chemotherapeutic potential. Genes Nutr. 2011, 6, 125-147. [CrossRef] [PubMed]

8. Bukhari, S.N.; Jantan, I.; Jasamai, M. Anti-inflammatory trends of 1,3-diphenyl-2-propen-1-one derivatives. Mini Rev. Med. Chem. 2013, 13, 87-94. [CrossRef] [PubMed]

9. Venkateswararao, E.; Sharma, V.K.; Yun, J.; Kim, Y.; Jung, S.-H. Anti-proliferative effect of chalcone derivatives through inactivation of NF-kB in human cancer cells. Bioorg. Med. Chem. 2014, 22, 3386-3392. [CrossRef] [PubMed]

10. Mahapatra, D.K.; Bharti, S.K.; Asati, V. Anti-cancer chalcones: Structural and molecular target perspectives. Eur. J. Med. Chem. 2015, 101, 496-524. [CrossRef] [PubMed]

11. Fang, Q.; Deng, L.; Wang, L.; Zhang, Y.; Weng, Q.; Yin, H.; Pan, Y.; Tong, C.; Wang, J.; Liang, G. Inhibition of mitogen-activated protein kinases/nuclear factor $\mathrm{kB}$-dependent inflammation by a novel chalcone protects the kidney from high fat diet-induced injuries in mice. J. Pharmacol. Exp. Ther. 2015, 355, 235-246. [CrossRef] [PubMed]

12. Mahapatra, D.K.; Asati, V.; Bharti, S.K. Chalcones and their therapeutic targets for the management of diabetes: Structural and pharmacological perspectives. Eur. J. Med. Chem. 2015, 92, 839-865. [CrossRef] [PubMed]

13. Mahapatra, D.K.; Bharti, S.K. Therapeutic potential of chalcones as cardiovascular agents. Life Sci. 2016, 148, 154-172. [CrossRef] [PubMed]

14. Rozmer, Z.; Perjési, P. Naturally occurring chalcones and their biological activities. Phytochem. Rev. 2016, 15, 87-120. [CrossRef]

15. Vogel, S.; Barbic, M.; Jürgenliemk, G.; Heilmann, J. Synthesis, cytotoxicity, anti-oxidative and anti-inflammatory activity of chalcones and influence of A-ring modifications on the pharmacological effect. Eur. J. Med. Chem. 2010, 45, 2206-2213. [CrossRef] [PubMed]

16. Iqbal, H.; Prabhakar, V.; Sangith, A.; Chandrika, B.; Balasubramanian, R. Synthesis, anti-inflamatory and antioxidant activity of ring-A-monosubstituted chalcone derivatives. Med. Chem. Res. 2014, 23, 4383-4394. [CrossRef]

17. Gupta, D.; Jain, D.K. Chalcone derivatives as potential antifungal agents: Synthesis, and antifungal activity. J. Adv. Pharm. Technol. Res. 2015, 6, 114-117. [CrossRef] [PubMed]

18. Bahekar, S.P.; Hande, S.V.; Agrawal, N.R.; Chandak, H.S.; Bhoj, P.S.; Goswami, K.; Reddy, M.V.R. Sulfonamide chalcones: Synthesis and in vitro exploration for therapeutic potential against Brugia malayi. Eur. J. Med. Chem. 2016, 124, 262-269. [CrossRef] [PubMed]

19. Joen, K.-H.; Lee, E.; Jun, K.-Y.; Eom, J.-E.; Kwak, S.Y.; Na, Y.; Kwon, Y. Neuroprotective effect of synthetic chalcone derivative as competitive dual inhibitors against $\mu$-calpain and cathepsin $\mathrm{B}$ through the downregulation of tau phosphorylation and insoluble A $\beta$ peptide formation. Eur. J. Med. Chem. 2016, 121, 433-444. [CrossRef] [PubMed]

20. Hammuda, A.; Shalaby, R.; Rovida, S.; Edmondson, D.E.; Binda, C.; Khalil, A. Design and synthesis of novel chalcones as potent selective monoamine oxidase-B inhibitors. Eur. J. Med. Chem. 2016, 114, 162-169. [CrossRef] [PubMed]

21. Kraege, S.; Stefan, K.; Juvale, K.; Ross, T.; Willmes, T.; Wiese, M. The combination of quinazoline and chalcone moieties leads to novel potent heterodimeric modulators of breast cancer resistance protein (BCRP/ABCG2). Eur. J. Med. Chem. 2016, 117, 212-229. [CrossRef] [PubMed]

22. Mirzaei, H.; Emami, S. Recent advances of cytotoxic chalconoids targeting tubulin polymerization: Synthesis and biological activity. Eur. J. Med. Chem. 2016, 121, 610-639. [CrossRef] [PubMed]

23. Cheng, X.; Wang, K.; Huang, S.; Zhang, H.; Zhang, H.; Wang, Y. Organic crystals with near-infrared amplified spontaneous emissions based on 2'-hydroxychalcone derivatives: Subtle structure modification but great property change. Angew. Chem. Int. Ed. 2015, 54, 8369-8373. [CrossRef] [PubMed]

24. Fang, D.; Cheng, J.; Fei, Z.; Gong, K.; Liu, Z. Synthesis of chalcones via Claisen-Schmidt condensation reaction catalyzed by acyclic acidic ionic liquids. Catal. Commun. 2008, 9, 1924-1927.

25. Qian, H.; Liu, D. Synthesis of chalcones via Claisen-Schmidt reaction catalyzed by sulfonic acid-functional ionic liquids. Ind. Eng. Chem. Res. 2011, 50, 1146-1149. [CrossRef] 
26. Otto, S.; Bertoncin, F.; Engberts, J.B.F.N. Lewis acid catalysis of a Diels-Alder reaction in water. J. Am. Chem. Soc. 1996, 118, 702-7707. [CrossRef]

27. Lu, Y.; Zhou, Y.; Lin, L.; Zheng, H.; Fu, K.; Liu, X.; Feng, X. N,N'-dioxide/nickel(II)-catalyzed asymmetric Diels-Alder reaction of cyclopentadiene with 2,3-dioxopyrrolidines and 2-alkenoyl pyridines. Chem. Commun. 2016, 52, 8255-8258. [CrossRef] [PubMed]

28. Gill, N.S.; Kaur, A.; Arora, R.; Dhawan, V.; Bali, M. Synthetic studies of novel azaflavanone derivatives and its biological activities. Curr. Res. Chem. 2012, 4, 88-98. [CrossRef]

29. Dias, T.A.; Duarte, C.L.; Lima, C.F.; Proença, M.F.; Pereira-Wilson, C. Superior anticancer activity of halogenated chalcones and flavonols over the natural flavonol quercetin. Eur. J. Med. Chem. 2013, 65, 500-510. [CrossRef] [PubMed]

30. Kupcewicz, B.; Jarzecki, A.A.; Małecka, M.; Krajewska, U.; Rozalski, M. Cytotoxic activity of substituted chalcones in terms of molecular electronic properties. Bioorg. Med. Chem. Lett. 2014, 24, 4260-4265. [CrossRef] [PubMed]

31. Batagin-Neto, A.; Lavarda, F.C. The correlation between electronic structure and antimalarial activity of alkoxylated and hydroxylated chalcones. Med. Chem. Res. 2014, 23, 580-586. [CrossRef]

32. Sharma, S.; Kaur, S.; Bansal, T.; Gaba, J. Review on synthesis of bioactive pyrazoline derivatives. Chem. Sci. Trans. 2014, 3, 861-875.

33. Li, C.W.; Shen, T.H.; Shih, T.-L. Reinvestigation of synthesis of halo-substituted 3-phenyl-1-(2-pyridyl)-2-propen-1-ones (azachalcones). A tandem reaction for formation of penta-substituted cyclohexanols. Tetrahedron 2017, 73, 4644-4652. [CrossRef]

34. Vaure, C.; Liu, Y. A comparative review of toll-like receptor 4 expression and functionality in different animal species. Front. Immunol. 2014, 5, 316. [CrossRef] [PubMed]

35. Lu, Y.C.; Yeh, W.C.; Ohashi, P.S. LPS/TLR4 signal transduction pathway. Cytokine 2008, 42, $145-151$. [CrossRef] [PubMed]

36. Arango, D.A.; Descoteaux, A. Macrophage cytokines: Involvement in immunity and infectious diseases. Front. Immunol. 2014, 5, 491-506. [CrossRef] [PubMed]

37. Ren, K.; Torres, R. Role of interleukin-1beta during pain and inflammation. Brain Res. Rev. 2009, 60, 57-64. [CrossRef] [PubMed]

38. Hunter, C.A.; Jones, S.A. IL-6 as a keystone cytokine in health and disease. Nat. Immunol. 2015, 16, 448-457. [CrossRef] [PubMed]

39. Beutler, B.A. The role of tumor necrosis factor in health and disease. J. Rheumatol. Suppl. 1999, 57, 16-21. [PubMed]

40. Schütze, S.; Wiegmann, K.; Machleidt, T.; Krönke, M. TNF-induced activation of NF-кB. Immunobiology 1995, 193, 193-203. [CrossRef]

41. Agarwal, S.; Reddy, G.V.; Reddanna, P. Eicosanoids in inflammation and cancer: The role of COX-2. Expert Rev. Clin. Immunol. 2009, 5, 145-165. [CrossRef] [PubMed]

42. Nishimoto, N.; Kishimoto, T. Inhibition of IL-6 for the treatment of inflammatory diseases. Curr. Opin. Pharmacol. 2004, 4, 386-391. [CrossRef] [PubMed]

43. Dinarello, C.A. Interleukin-1 in the pathogenesis and treatment of inflammatory diseases. Blood 2011, 117, 3720-3732. [CrossRef] [PubMed]

44. Sedger, L.M.; McDermott, M.F. TNF and TNF-receptors: From mediators of cell death and inflammation to therapeutic giants-past, present and future. Cytokine Growth Factor Rev. 2014, 25, 453-472. [CrossRef] [PubMed]

45. Bertolini, A.; Ottani, A.; Sandrini, M. Selective COX-2 inhibitors and dual acting anti-inflammatory drugs: Critical remarks. Curr. Med. Chem. 2002, 9, 1033-1043. [CrossRef] [PubMed]

46. Chauhan, V.; Chaudhary, D.; Pathak, U.; Saxena, N.; Dhaked, R.K. In silico discovery and validation of amide based small molecule targeting the enzymatic site of shiga toxin. J. Med. Chem. 2016, 59, 10763-10773. [CrossRef] [PubMed]

47. Rajput, J.K.; Kaur, G. Silicotungstic acid catalysed Claisen Schmidt condensation reaction: An efficient protocol for synthesis of 1,3-diaryl-2-propenones. Tetrahedron Lett. 2012, 53, 646-649. [CrossRef]

48. Chen, F.C.; Yang, C.H. Haloflavones. Taiwan Pharm. J. 1951, 3, 39-41. 
49. Lu, M.Y.; Chen, C.C.; Lee, L.Y.; Lin, T.W.; Kuo, C.F. N6-(2-hydroxyethyl)-adenosine in medicinal mushroom Cordyceps cicadae attenuates lipopolysaccharide-stimulated pro-inflammatory responses by suppressing TLR4-mediated NF-kB signaling pathways. J. Nat. Prod. 2015, 78, 2452-2460. [CrossRef] [PubMed]

50. Livak, K.J.; Schmittgen, T.D. Analysis of relative gene expression data using real-time quantitative PCR and the 2(-delta delta c(T)) method. Methods 2001, 25, 402-408. [CrossRef] [PubMed]

(C) 2018 by the authors. Licensee MDPI, Basel, Switzerland. This article is an open access article distributed under the terms and conditions of the Creative Commons Attribution (CC BY) license (http://creativecommons.org/licenses/by/4.0/). 